\title{
Assessment of Aortic Root Mechanics in Hypertensive Patients by Speckle Tracking Echocardiography
}

\author{
Mahmoud Kamel Ahmed*, Kareem Fathy Adam, Wassam Eldin El-Shafey \\ Department of Cardiology, Menoufia University, Menoufia, Egypt \\ Email: *mahmoudkamel35@gmail.com,mahmoud.gabr@med.menofia.edu.eg,dr_wesamhadad@yahoo.com, \\ ka061464@gmail.com
}

How to cite this paper: Ahmed, M.K. Adam, K.F. and El-Shafey, W.E. (2019) Assessment of Aortic Root Mechanics in Hypertensive Patients by Speckle Tracking Echocardiography. World Journal of Cardiovascular Diseases, 9, 212-222.

https://doi.org/10.4236/wjcd.2019.93019

Received: February 18, 2019

Accepted: March 19, 2019

Published: March 22, 2019

Copyright $\odot 2019$ by author(s) and Scientific Research Publishing Inc. This work is licensed under the Creative Commons Attribution International License (CC BY 4.0).

http://creativecommons.org/licenses/by/4.0/

\begin{abstract}
Objectives: Hypertension is a major risk factor for several cardiovascular diseases, including stroke, atherosclerosis and coronary heart disease. Remodeling of the aortic root may be expected to occur in hypertensive subjects as a result of increased stress on the aortic wall due to the repeated hemodynamic overload. Two-dimensional speckle tracking echocardiography is a promising new imaging modality. The aim of this study is to assess aortic root mechanics in relation to left ventricular mechanics in hypertensive patients by speckle tracking echocardiography. Methods: The study included 50 individuals, 30 patients with hypertension compared with 20 age and sex matched healthy volunteers as control group. For both groups, conventional echo was done and speckle tracking echocardiography of the LV including longitudinal, circumferential, radial strain, LV rotation and the longitudinal strain of the ascending aorta and aortic distensibility were measured. Results: Aortic longitudinal strain of both anterior and posterior walls, and also LV longitudinal peak systolic strain were lower significantly in patient group, and also in the same group, the apical rotation was higher than control; aortic longitudinal strain was negatively correlated with E/E, and LV global longitudinal strain was correlated positively with septal annular E wave peak velocity and with aortic distensibility. Conclusion: Hypertension significantly lowers ascending aortic longitudinal strain and the changes are correlated significantly with LV longitudinal systolic function and with echo parameters of elevated LV filling pressure.
\end{abstract}

\section{Keywords}

Hypertension, Aorta, 2-Dimensional Speckle Tracking Echocardiography 


\section{Introduction}

Hypertension is a major risk factor for several cardiovascular diseases including stroke, atherosclerosis and coronary heart disease [1].

Elastic properties of the aorta are important factors supporting LV function. The functions of the aorta are not only those of a blood conduit, but also an important modulator of the entire cardiovascular system [2].

Remodeling of the aortic root may be expected to occur in hypertensive subjects as a result of increased stress on the aortic wall due to the repeated hemodynamic overload [3] [4].

Two-dimensional speckle tracking echocardiography is a promising new imaging modality. It permits offline assessment of tissue velocities and deformation parameters such as strain and strain rate. It is well accepted that these parameters provide important insights into systolic and diastolic function, myocardial mechanics and many other pathophysiological processes of the heart [5].

The study aims to assess aortic root longitudinal deformation in relation to left ventricular mechanics in hypertensive patients by speckle tracking echocardiography.

\section{Patients and Methods}

Study enrolled 75 patients. 25 patients were excluded due to poor echocardiographic window. So only 50 patients were enrolled, 30 of which were hypertensive and were compared with twenty age and sex-matched healthy individuals without detectable cardiovascular risk factor and not receiving any medication. The study was performed on patients presented to Cardiology outpatient clinic, Menoufia University Hospitals.

Inclusion criteria: patients with primary hypertension with more than one-year duration and controlled by antihypertensive medications except beta blocker, normal LV systolic function (left ventricular ejection fraction $>50 \%$ ) on echocardiogram as well as normal sinus rhythm on ECG. Exclusion criteria: patients with arrhythmia, coronary artery disease, significant (more than mild) primary valvular disease, cardiomyopathy, severe renal and hepatic diseases and patients with poor echogenic window.

All participants were subjected to full history taking, thorough clinical examination, resting 12-lead surface ECG, Conventional echocardiographic examination was done by using the commercially available Vivid 9, General Electric Healthcare, GE Vingmed, Norway equipped with a 1.7 - $4 \mathrm{MHz}$ phased-array transducer. Echocardiographic imaging was obtained in the parasternal longand short-axis, and apical 2, 3 and 4-chamber views using standard transducer positions. LV end-diastolic and systolic diameters, septal and posterior walls thickness, ejection fraction, aortic and left atrial diameters were measured in accordance with the recommendations of the American Society of Echocardiography [6] Pulsed and continuous-wave Doppler was used for valvular assessment. Doppler Tissue imaging of the septal mitral annulus was obtained from the apic- 
al 4-chamber view. Early and late diastolic wave peak velocities (e' \& a') and the ratio of early diastolic mitral flow peak velocity to early diastolic septal annular peak velocity was measured (E/e') also systolic $S$ wave peak velocity, isovolumic contraction and relaxation times were measured.

$L V$ Deformation: three cycles from apical views: 4,2 and 3 chamber views were taken and another three cycles from the short axis view at the level of the LV papillary muscles and LV apical level for measuring circumferential and radial strain and also for measuring rotation, twist and untwist ratio.

Frame rate was selected between $40-90$ or at least $40 \%$ of HR. Then after activation of automated function imaging (AFI), digital data were transferred for off-line analysis, using Vivid Nine System Echo Pac, GE Vingmed, Horton, Norway.

Aortic Longitudinal Stain: Tracking of the anterior and posterioraortic wall from the left parasternal long axis view, started from the sino-tubular junction and $3 \mathrm{~cm}$ thereafter and post-processing analyzed with 2D-strain using off line analysis by Echo pack system where the peak velocity of positive wave that occur just after aortic valve closure was measured.

Aortic Distensibility (AoD): AoD was measured by putting M-mode line 3 $4 \mathrm{~cm}$ above the aortic valve from a transthoracic parasternal long-axis view, at the time of maximum aortic anterior motion, and at the peak of the QRS complex, respectively and was calculated as using the formula: $2 \times$ (change in aortic diameter $) /[($ diastolic aortic diameter $) \times($ arterial pulse pressure $)[7]$.

\section{Statistical Analysis}

Data were analyzed using SPSS software. Quantitative data expressed as mean and standard deviation Chi-square test student test, Mann whiney $U$ test, Kruskal Walls test and correlation coefficient test.

\section{Results}

The study population consisted of 75 patients. However, 50 patients completed the study after exclusion of another 25 patients due to inability of the system to obtain good result.

Male sex represented 57\% of group A (17 patients) with mean age $51.5 \mathrm{y}$ with no significant difference between both groups as regarding age, sex, and BWI but smoking is more in hypertensive group (Table 1).

As regarding conventional echo cardiographic parameters, septal and posterior walls thickness, RWT, LA and aortic diameters were significantly higher in-patient group (Table 2).

Regarding aortic distensibility: in patient group, systolic and diastolic blood pressure and pulse pressure were higher while the aortic distensibility was lower in comparison to control group (Table 2).

The septal annular E' and $S$ waves peak velocities were lower while E/e' ratio was higher in-patient group (Table 3). 
Table 1. Demographic data of both groups.

\begin{tabular}{|c|c|c|c|c|c|c|}
\hline \multicolumn{2}{|c|}{ Parameter } & \multicolumn{2}{|c|}{$\begin{array}{l}\text { Group A } \\
(\mathrm{n}=20)\end{array}$} & \multicolumn{2}{|c|}{$\begin{array}{l}\text { Group B } \\
(\mathrm{n}=30)\end{array}$} & \multirow{4}{*}{$\begin{array}{c}P \text {-Value } \\
0.19\end{array}$} \\
\hline & & \multirow{3}{*}{$\begin{array}{c}\text { No. } \\
9 \\
11\end{array}$} & \multirow{2}{*}{$\begin{array}{c}\% \\
45 \%\end{array}$} & \multirow{2}{*}{$\begin{array}{c}\text { No. } \\
13\end{array}$} & \multirow{2}{*}{$\begin{array}{c}\% \\
43 \%\end{array}$} & \\
\hline Sex & Female & & & & & \\
\hline [No. (\%)] & Male & & $55 \%$ & 17 & $57 \%$ & \\
\hline $\begin{array}{c}\text { Age } \\
\text { (years) }\end{array}$ & Mean \pm SD & \multicolumn{2}{|c|}{$45.85 \pm 12.31$} & \multicolumn{2}{|c|}{$51.57 \pm 10.93$} & 0.06 \\
\hline \multirow{2}{*}{$\begin{array}{c}\text { Hypertension } \\
{[\text { No. (\%)] }}\end{array}$} & Hypertensive & 0 & $0.0 \%$ & 30 & $100 \%$ & \multirow{2}{*}{$<0.001$} \\
\hline & Non-hypertensive & 20 & $100 \%$ & 0 & $0.0 \%$ & \\
\hline \multirow{2}{*}{ Smoker } & Smoker & 5 & $25 \%$ & 18 & $60 \%$ & \multirow{2}{*}{0.043} \\
\hline & Non-smoker & 15 & $75 \%$ & 12 & $40 \%$ & \\
\hline $\begin{array}{c}\text { BMI } \\
\left(\mathrm{kg} / \mathrm{m}^{2}\right)\end{array}$ & Mean \pm SD & \multicolumn{2}{|c|}{$27.12 \pm 4.4$} & \multicolumn{2}{|c|}{$29.23 \pm 4.4$} & 0.103 \\
\hline
\end{tabular}

BMI: Body mass index.

Table 2. Comparison of conventional echocardiographic parameters both groups.

\begin{tabular}{|c|c|c|c|}
\hline Variable & $\begin{array}{l}\text { Group A } \\
(\mathrm{n}=20)\end{array}$ & $\begin{array}{l}\text { Group B } \\
(\mathrm{n}=30)\end{array}$ & $P$-Value \\
\hline $\operatorname{IVSd}(\mathrm{cm})$ & $0.91 \pm 0.18$ & $1.16 \pm 0.17$ & $<0.001$ \\
\hline $\operatorname{LVIDd}(\mathrm{cm})$ & $4.86 \pm 0.38$ & $4.74 \pm 0.5$ & 0.374 \\
\hline LVIDs (cm) & $3.11 \pm 0.28$ & $3.0 \pm 0.37$ & 0.409 \\
\hline LVPWd $(\mathrm{cm})$ & $0.9(0.8,1.1)$ & $1.2(1.1,1.3)$ & $<0.001$ \\
\hline $\mathrm{EDV}(\mathrm{mL})$ & $111(94.5,129)$ & $96(86,114)$ & 0.113 \\
\hline ESV (mL) & $38(31.5,45)$ & $35(27,41)$ & 0.184 \\
\hline $\operatorname{LVMI}\left(\mathrm{g} / \mathrm{m}^{2}\right)$ & $91 \pm 26.13$ & $110.37 \pm 29.3$ & 0.021 \\
\hline LVRWT & $0.39 \pm 0.09$ & $0.5 \pm 0.08$ & $<0.001$ \\
\hline $\mathrm{EF}(\%)$ & $66(62,69)$ & $63(61,72)$ & 0.641 \\
\hline $\mathrm{SV}(\mathrm{mL})$ & $74.85 \pm 15.88$ & $69.37 \pm 20$ & 0.309 \\
\hline FS (\%) & $36.5(33.5,38.5)$ & $34(33,42)$ & 0.605 \\
\hline $\mathrm{LA}(\mathrm{mm})$ & $35.45 \pm 4.4$ & $40.9 \pm 5.23$ & $<0.001$ \\
\hline Ao $(\mathrm{mm})$ & $28(27,29)$ & $31(28,35)$ & $<0.001$ \\
\hline $\mathrm{E}(\mathrm{cm} / \mathrm{s})$ & $0.81 \pm 0.129$ & $0.58 \pm 0.176$ & $<0.001$ \\
\hline $\mathrm{A}(\mathrm{cm} / \mathrm{s})$ & $0.56 \pm 0.146$ & $0.70 \pm 0.179$ & $<0.06$ \\
\hline $\mathrm{E} / \mathrm{A}$ & $1.54(1.23,1.68)$ & $0.67(0.57,0.78)$ & $<0.001$ \\
\hline Systolic BP & $122.55 \pm 10.13$ & $150.00 \pm 13.18$ & 0.02 \\
\hline Diastolic BP & $70.00 \pm 2.79$ & $100.55 \pm 12.39$ & 0.01 \\
\hline Pulse pressure & $40.55 \pm 10.00$ & $65.45 \pm 1.58$ & 0.003 \\
\hline Aortic Systolic diameter & $28.94 \pm 0.44$ & $31.56 \pm 0.18$ & 0.04 \\
\hline Aortic diastolic diameter & $25.47 \pm 0.32$ & $30.59 \pm 0.13$ & 0.01 \\
\hline Pulsatile change & $4 \pm 0.20$ & $3 \pm 0.12$ & 0.03 \\
\hline Distensibility, $10^{-6} \cdot \mathrm{cm}^{2} \cdot$ dyne $^{-1}$ & $5.5 \pm 2.5$ & $2.1 \pm 2.3$ & 0.001 \\
\hline
\end{tabular}

IVSD: interventricular septal thickness at end diastole, LVPW: left ventricular posterior wall thickness, LVEDD: left ventricular end diastolic dimension, LVESD: left ventricular end systolic dimension, LVEDV: left ventricular end diastolic volume, LVESV: left ventricular end systolic volume, LVEF: left ventricular ejection fraction. LA: left atrium, E: early peak pulsed doppler velocity on mitral valve, A: late pulsed doppler velocity on mitral valve. 
Table 3. Comparison as regard mitral annular TDI echocardiography parameters between study subgroups.

\begin{tabular}{ccccc}
\hline Variable & $\begin{array}{c}\text { Group A } \\
(\mathbf{n}=\mathbf{2 0})\end{array}$ & $\begin{array}{c}\text { Group B } \\
(\mathbf{n}=\mathbf{3 0})\end{array}$ & Test of sig.* & $\boldsymbol{P}$-Value \\
\hline$\grave{\mathrm{e}}(\mathrm{cm} / \mathrm{s})$ & $12.5(10,15)$ & $6(5,7)$ & $\mathrm{Z}=-5.193$ & $<0.001$ \\
à $(\mathrm{cm} / \mathrm{s})$ & $8.2 \pm 2.1$ & $11.3 \pm 2.5$ & $\mathrm{t}=-4.583$ & $<0.001$ \\
è/à & $1.56(1.27,1.73)$ & $0.53(0.41,0.75)$ & $\mathrm{Z}=-5.665$ & $<0.001$ \\
E/è & $6.84 \pm 1.69$ & $9.69 \pm 3.08$ & $\mathrm{t}=-4.199$ & $<0.001$ \\
$\mathrm{~S}(\mathrm{~cm} / \mathrm{s})$ & $9(8,9)$ & $8(7,9)$ & $\mathrm{Z}=-2.051$ & $\mathbf{0 . 0 4}$ \\
IC time (ms) & $72.9 \pm 15.53$ & $67.9 \pm 14.78$ & $\mathrm{t}=1.149$ & 0.256 \\
IR time (ms) & $69.7 \pm 13.4$ & $77.1 \pm 17.2$ & $\mathrm{t}=-1.622$ & 0.111 \\
S wave time (ms) & $271(266,300)$ & $266(240,289)$ & $\mathrm{Z}=-1.665$ & 0.096 \\
\hline
\end{tabular}

*Continuous variables with normal distribution are presented as mean and standard deviation, while continuous variables with non-normal distributions are presented as median and interquartile range. $t$ : Independent-Samples T test. Z: Mann Whitney U test.

Aortic longitudinal strain of both anterior and posterior walls also LV longitudinal peak systolic strain were lower significantly in-patient group also in the same group the apical rotation was higher than control (Table 4, Figure 1 \& Figure 2).

As regards correlation analysis: aorta longitudinal strain was negatively correlated with E/e', and LV global longitudinal strain and correlated positively with septal annular e' wave peak velocity and with aortic distensibility (Table 5).

\section{Discussion}

This study based on STE assessment of ascending aorta in hypertensive patients, The main findings of this study were: first: longitudinal strain of ascending aortic walls and aortic distensibility were affected and lower in hypertensive patients compared to non-hypertensive individual, second: significant negative correlations between GLS of the aorta and LV averaged global longitudinal peak systolic strain, Third: aortic LG was positively correlated with $\mathrm{E}$ annular velocity and negatively correlated with $\mathrm{E} / \mathrm{e}$, aortic diameter and aortic distensibility.

Vascular mechanics was first conceived by Oishi et al. [1] in 2008 at the level of the abdominal aorta, and since then, others have demonstrated that the circumferential deformation of the proximal thoracic ascending aorta [2] [3], the descending thoracic aorta [4], and the carotid arteries [5] could be measured.

An increase in arterial stiffness causes LV hypertrophy by elevating the systolic blood pressure, resulting in an impaired LV relaxation. According to other studies the aortic stiffness increased with age in relatively healthy individuals, and its increasing rate became marked in the presence of hypertension [6] [7] remodeling of the aortic root may be expected to occur in hypertensive subjects because of increased stress on the aortic wall due to the repeated hemodynamic overload [8] [9]. 
Table 4. Comparison as regard 2D-STE parameters of left ventricular function and aortic root mechanics between study subgroups.*

\begin{tabular}{|c|c|c|c|c|c|}
\hline & Variable & $\begin{array}{l}\text { Group A } \\
(\mathrm{n}=20)\end{array}$ & $\begin{array}{l}\text { Group B } \\
(\mathrm{n}=30)\end{array}$ & Test of sig. * & P-Value \\
\hline \multicolumn{6}{|c|}{ Lt ventricular function: } \\
\hline$\checkmark$ & GLPS-LAX (\%) & $-19.17 \pm 3.71$ & $-16.48 \pm 2.94$ & $\mathrm{t}=-2.091$ & 0.041 \\
\hline$\checkmark$ & GLPS-A4C (\%) & $-19.86 \pm 2.6$ & $-18.0 \pm 4.15$ & $\mathrm{t}=-1.95$ & 0.041 \\
\hline$\checkmark$ & GLPS-A2C (\%) & $-19.85 \pm 2.47$ & $-16.8 \pm 2.35$ & $\mathrm{Z}=2.387$ & 0.017 \\
\hline$\checkmark$ & GLPS-Average (\%) & $-19.35 \pm 2.52$ & $-17.4 \pm 2.71$ & $\mathrm{t}=-2.565$ & 0.014 \\
\hline$\checkmark$ & $\begin{array}{l}\text { Apical peak circumferential } \\
\text { strain }(\%)\end{array}$ & $-21.32 \pm 8.92$ & $-25 \pm 11.36$ & $\mathrm{t}=1.219$ & 0.229 \\
\hline$\checkmark$ & Apical peak radial strain (\%) & $17.64 \pm 6.8$ & $24.63 \pm 7.2$ & $Z=0.891$ & 0.373 \\
\hline$\checkmark$ & $\begin{array}{l}\text { Basal peak circumferential } \\
\text { strain }(\%)\end{array}$ & $-15.04 \pm 3.8$ & $-15.08 \pm 4.48$ & $t=0.029$ & 0.977 \\
\hline$\checkmark$ & Basal peak radial strain (\%) & $25.94 \pm 6.66$ & $23.1 \pm 5.6$ & $Z=-2.099$ & 0.06 \\
\hline$\checkmark$ & Apical rotation $\left({ }^{\circ}\right)$ & $8.39 \pm 4.24$ & $10.0 \pm 5.6$ & $Z=0.168$ & 0.04 \\
\hline$\checkmark$ & Basal rotation $\left({ }^{\circ}\right)$ & $-3.18 \pm 3.4$ & $-4.11 \pm 2.2$ & $\mathrm{Z}=-0.228$ & 0.820 \\
\hline$\checkmark$ & Torsion time (ms) & $504.5 \pm 71.9$ & $464.5(374,543)$ & $Z=-1.249$ & 0.212 \\
\hline$\checkmark$ & Peak twist $\left({ }^{\circ}\right)$ & $77.37 \pm 35.97$ & $91.67 \pm 34.56$ & $\mathrm{t}=-1.410$ & 0.165 \\
\hline$\checkmark$ & Time to peak twist (ms) & $351.25 \pm 61.59$ & $325(249,458)$ & $Z=-0.486$ & 0.627 \\
\hline$\checkmark$ & Peak untwist $\left({ }^{\circ}\right)$ & $-77.58 \pm 29.36$ & $-108.01 \pm 47.69$ & $\mathrm{t}=2.791$ & 0.008 \\
\hline$\checkmark$ & Time to peak untwist (ms) & $593.4 \pm 101.24$ & $620(469,661)$ & $Z=0.337$ & 0.736 \\
\hline$\checkmark$ & Aortic root mechanics: & & & & \\
\hline$\checkmark$ & $\begin{array}{l}\text { Anterior wall longitudinal } \\
\text { strain (\%) }\end{array}$ & $25.23 \pm 18.9$ & $20.5 \pm 11.1$ & $\mathrm{t}=2.94$ & 0.004 \\
\hline$\checkmark$ & $\begin{array}{l}\text { Posterior wall longitudinal } \\
\text { strain (\%) }\end{array}$ & $22.95 \pm 15.6$ & $17.05 \pm 101.3$ & $\mathrm{t}=4.74$ & 0.01 \\
\hline$\checkmark$ & Global aortic strain (\%) & $23.3 \pm 14.5$ & $18.5 \pm 9.8$ & $\mathrm{t}=3.5$ & 0.008 \\
\hline
\end{tabular}

Continuous variables with normal distribution are presented as mean and standard deviation, while continuous variables with non-normal distributions are presented as median and interquartile range. t: Independent-Samples T test. Z: Mann Whitney U test.

\subsection{Relation of Aortic Deformation with LV Deformation and Systolic Function}

Increased aortic stiffness has been linked to impaired LV systolic function, particularly along the LV long axis in several previous studies [10]. The relation is often attributed to increased hemodynamic load imposed by stiffer arteries [11] [12]. Direct mechanical ventricular-vascular coupling provides an alternative explanation for the observed relation between aortic stiffness and LV systolic function.

Systolic contraction shortens the LV long axis by pulling the aortic annulus and sinotubular junction of the aorta towards the LV apex, which moves minimally during systole [13] [14] [15] [16]. The combination of aortic annulus displacement along with minimal movement of the aortic arch implies that there is 


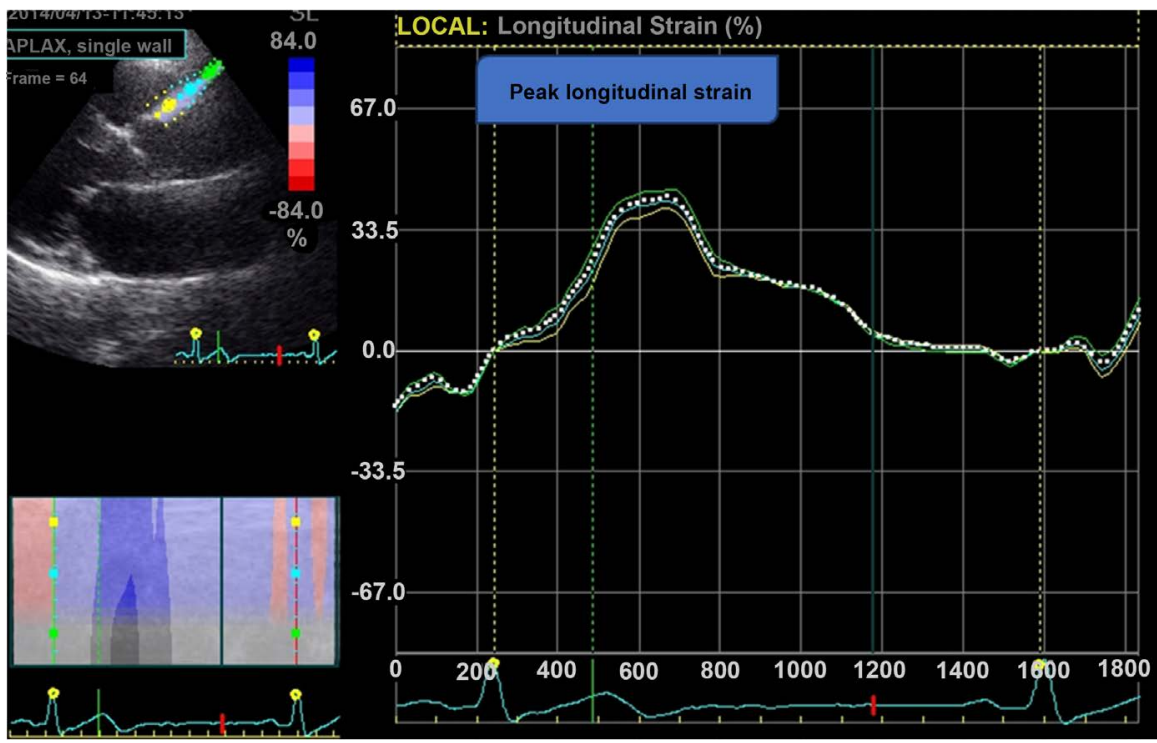

Figure 1. Aortic anterior wall longitudinal strain of one of control individual.

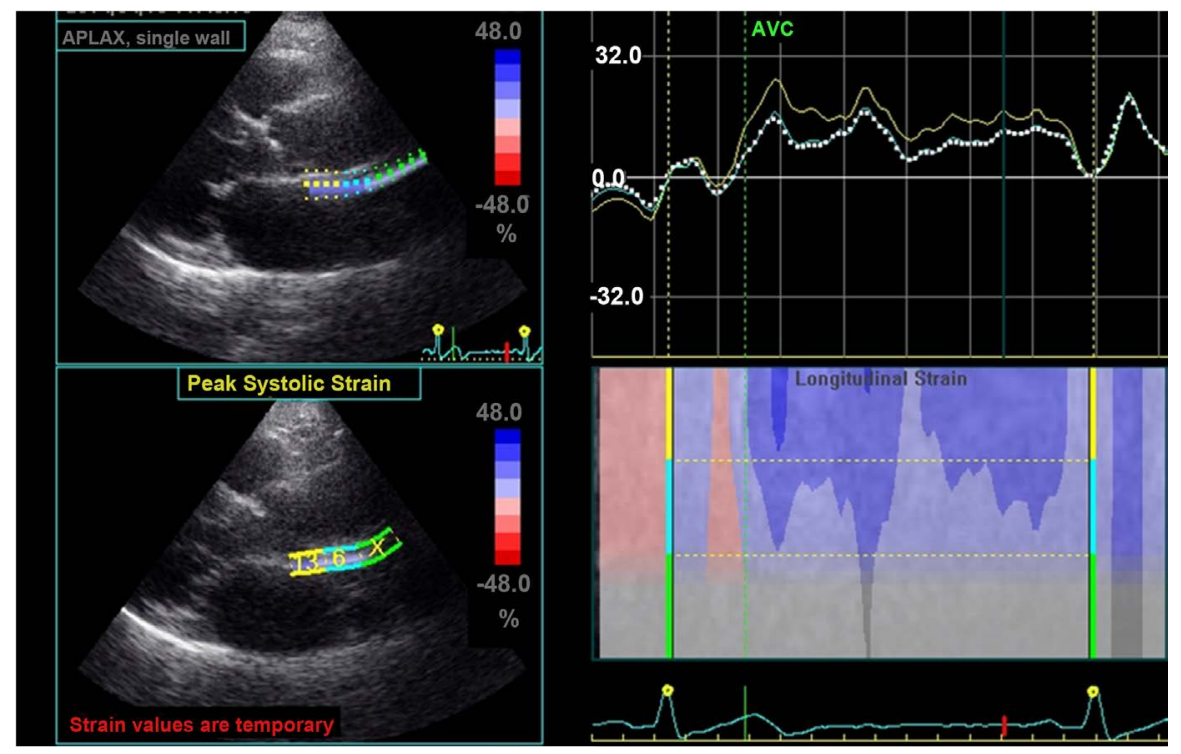

Figure 2. Aortic posterior wall longitudinal strain of one of patient group.

considerable longitudinal stretch of the ascending aorta during systole [16] [17] [18]. Aortic stretch increases from the beginning until the end of systole and imposes a progressive systolic load on the heart [11] [15]. If the aorta stiffens, the heart must contract with greater long-axis force in order to produce the same amount of aortic displacement; for a given LV contraction strength, a stiff aorta would be displaced and stretched less than a compliant aorta would. Therefore, LV long-axis shortening and GLS may be reduced when pulling against a stiffer aorta because of a potential mechanical ventricular-vascular interaction [18]. Vanessa Bell et al. [10] found that CFPWV (carotid-femoral pulse wave velocity) as a measurement parameter of aortic stiffness was associated with GLS and not global circumferential strain, which may indicate that 
Table 5. Comparison between aortic longitudinal strain and different echo cardiographic parameters.

\begin{tabular}{|c|c|c|}
\hline \multirow[t]{2}{*}{ Parameter } & \multicolumn{2}{|c|}{ Global aortic wall longitudinal strain } \\
\hline & $r$ & $P$-value \\
\hline LV end-diastolic volume & 0.063 & 0.664 \\
\hline LV end-systolic volume & 0.166 & 0.249 \\
\hline $\mathrm{e}^{\prime}$ & 0.358 & 0.011 \\
\hline $\mathrm{E} / \mathrm{è}$ & -0.347 & 0.013 \\
\hline Apical circumferential strain & 0.186 & 0.195 \\
\hline Apical radial strain & -0.046 & 0.752 \\
\hline Basal circumferential strain & 0.121 & 0.404 \\
\hline Basal radial strain & 0.037 & 0.798 \\
\hline Peak twist & -0.166 & 0.250 \\
\hline Time to peak twist & -0.170 & 0.238 \\
\hline Peak untwist & 0.195 & 0.176 \\
\hline Time to peak untwist & -0.082 & 0.570 \\
\hline Averaged GLPS & -0.443 & 0.001 \\
\hline Distensibility, $10^{-6} \cdot \mathrm{cm}^{2} \cdot$ dyne $\mathrm{e}^{-1}$ & 0.362 & 0.001 \\
\hline
\end{tabular}

long-axis function of the LV is more closely linked with global aortic wall stiffness than is short-axis function, and this go with our result in which aortic longitudinal strain correlated with LV longitudinal strain but there is no significant correlation with LV circumferential and radial strain.

\subsection{The relation between Aortic Deformation and Diastolic Function}

In our study aortic LG was negatively correlated with $\mathrm{E} / \mathrm{e}^{\prime}$ which is an echo parameter of elevated LV filling pressure and it positively correlated with e' annular velocity.

Abhayaratna et al. [19] investigated the relation of arterial stiffness to LV diastolic dysfunction in a sample of 188 elderly individuals and observed a significant correlation between central pulse pressure and severity of diastolic dysfunction and concluded that increased arterial stiffness was associated with more severe left ventricular diastolic dysfunction.

Bernhard M. Kaess et al. [20] found that CFPWV is related to LV diastolic function. they observed a consistent association of higher central pulse pressure with higher E/E' (a surrogate measure of elevated LV filling pressure).

There are two possible explanations for relation of diastolic dysfunction to aortic deformation: First, parallel changes may occur in the cardiac and aortic walls due to hypertension. The second possible explanation is that increased aortic stiffness may also increase afterload, inducing myocardial structural changes 
of the left ventricle and, through that, left ventricular diastolic dysfunction. The most important factor in developing cardiac hypertrophy is increased end systolic wall stress. End systolic wall stress is influenced not only by the geometric properties of the ventricle but also by aortic stiffness [21] [22].

\subsection{The Relation between Aortic Deformation and Aortic Distensibility}

In our study the aortic distensibility was lower in-patient group and the aortic longitudinal strain was correlated positively with aortic distensibility.

M. Eren et al. [22] and Costa Stratos et al. [23] found that aortic distensibility (measured by M. mode) was lower in hypertensive patient and more lowered in hypertensive diabetic patients.

Aortic distensibility can be measured by other techniques as MRI and also it was found to be lowered in hypertensive patient as found from Malayeri $A$ Astudy [24] who study aortic distensibility abnormalities in different cardiovascular risk factors and hypertension was inversely correlated with hypertriton and older age.

\subsection{Study Limitations}

our study has several limitations first; it depends on a relatively small number of patients as many patients were excluded (30\% of the all enrolled patients) due to inadequate images for analysis as till now there is no specific software for analysis of the aortic wall and we depends on LV software which analysis thicker wall and this leads to inability of the system to analysis the thin aortic wall in many patients. Second, our study included patients with different onset, severity, and treatment modalities of HTN which may have a potential influence on our study results, however we excluded patients controlled on beta blocker due to its known potential effect in affecting the LV strain. Third, this study was single-center study, and we in need for multicenter studies to identify and analyze all potential confounding factors.

\section{Conclusion}

Hypertension significantly lowers the ascending aortic longitudinal strain and the changes are correlated significantly with LV longitudinal systolic function and with echo parameters of elevated LV filling pressure.

\section{Conflicts of Interest}

The authors declare no conflicts of interest regarding the publication of this paper.

\section{References}

[1] Oishi, Y., Mizuguchi, Y., Miyoshi, H., Iuchi, A., Nagase, N. and Oki, T. (2008) A Novel Approach to Assess Aortic Stiffness Related to Changes in Aging Using a 
Two-Dimensional Strain Imaging. Echocardiography, 25, 941-945. https://doi.org/10.1111/j.1540-8175.2008.00725.x

[2] Teixeira, R., Monteiro, R., Garcia, J., et al. (2014) Feasibility of Aortic Arch Mechanics: A Study in Normal Subjects. European Heart Journal-Cardiovascular Imaging, 15, ii9-ii12.

[3] Teixeira, R., Monteiro, R., Garcia, J., et al. (2014) Aortic Arch Mechanics in Hypertensive Patients versus Controls, a Two Dimensional Speckle-Tracking Study. European Heart Journal-Cardiovascular Imaging, 15, ii235-ii264.

[4] Petrini, J., Jenner, J., Rickenlund, A., et al. (2014) Elastic Properties of the Descending Aorta in Patients with a Bicuspid or Tricuspid Aortic Valve and Aortic Valvular Disease. Journal of the American Society of Echocardiography, 27, 393-404. https://doi.org/10.1016/j.echo.2013.12.013

[5] Yuda, S., Kaneko, R., Muranaka, A., et al. (2011) Quantitative Measurement of Circumferential Carotid Arterial Strain by Two-Dimensional Speckle Tracking Imaging in Healthy Subjects. Echocardiography, 28, 899-906.

https://doi.org/10.1111/j.1540-8175.2011.01443.x

[6] Lang, R.M., Bierig, M., Devereux, R.B., et al. (2006) Recommendations for Chamber Quantification. European Journal of Echocardiography, 7, 79-108.

https://doi.org/10.1016/j.euje.2005.12.014

[7] Stefanadis, C., Stratos, C., Boudoulas, H., et al. (1994) Distensibility of the Ascending Aorta in Coronary Artery Disease and Changes after Nifedipine Administration. Chest, 105, 1017-1023. https://doi.org/10.1378/chest.105.4.1017

[8] Erbel, R., Aboyans, V., Boileau, C., et al. (2014) 2014 ESC Guidelines on the Diagnosis and Treatment of Aortic Diseases: Document Covering Acute and Chronic Aortic Diseases of the Thoracic and Abdominal Aorta of the Adult. The Task Force for the Diagnosis and Treatment of Aortic Diseases of the European Society of Cardiology. European Heart Journal, 35, 2873-2926.

https://doi.org/10.1093/eurheartj/ehu281

[9] Baguet, J.P., Chavanon, O., Sessa, C., et al. (2012) European Society of Hypertension Scientific Newsletter: Hypertension and Aortic Diseases. Journal of Hypertension, 30, 440-443. https://doi.org/10.1097/HJH.0b013e32834f867a

[10] Bell, V., McCabe, E.L., Larson, M.G., et al. (2017) Relations between Aortic Stiffness and Left Ventricular Mechanical Function in the Community. Journal of the American Heart Association, 6, pii:e004903. https://doi.org/10.1161/JAHA.116.004903

[11] Kim, H.L., Seo, J.B., Chung, W.Y., et al. (2015) Independent Association between Brachial-Ankle Pulse Wave Velocity and Global Longitudinal Strain of Left Ventricle. The International Journal of Cardiovascular Imaging, 31, 1563-1570. https://doi.org/10.1007/s10554-015-0744-5

[12] Krishnasamy, R., Hawley, C.M., Stanton, T., et al. (2015) Left Ventricular Global Longitudinal Strain Is Associated with Cardiovascular Risk Factors and Arterial Stiffness in Chronic Kidney Disease. BMC Nephrology, 16, 106. https://doi.org/10.1186/s12882-015-0098-1

[13] Beller, C.J., Labrosse, M.R., Thubrikar, M.J. and Robicsek, F. (2004) Role of Aortic Root Motion in the Pathogenesis of Aortic Dissection. Circulation, 109, 763-769. https://doi.org/10.1161/01.CIR.0000112569.27151.F7

[14] Kozerke, S., Scheidegger, M.B., Pedersen, E.M. and Boesiger, P. (1999) Heart Motion Adapted Cine Phase-Contrast Flow Measurements through the Aortic Valve. Magnetic Resonance in Medicine, 42, 970-978.

https://doi.org/10.1002/(SICI)1522-2594(199911)42:5<970::AID-MRM18>3.0.CO;2$\underline{\mathrm{I}}$ 
[15] Bell, V., Mitchell, W.A., Sigurethsson, S., et al. (2014) Longitudinal and Circumferential Strain of the Proximal Aorta. Journal of the American Heart Association, 3 , e001536. https://doi.org/10.1161/JAHA.114.001536

[16] Weber, T.F., Muller, T., Biesdorf, A., et al. (2014) True Four-Dimensional Analysis of Thoracic Aortic Displacement and Distension Using Model-Based Segmentation of Computed Tomography Angiography. The International Journal of Cardiovas cular Imaging, 30, 185-194. https://doi.org/10.1007/s10554-013-0307-6

[17] Morrison, T.M., Choi, G., Zarins, C.K. and Taylor, C.A. (2009) Circumferential and Longitudinal Cyclic Strain of the Human Thoracic Aorta: Age-Related Changes. Journal of Vascular Surgery, 49, 1029-1036. https://doi.org/10.1016/j.jvs.2008.11.056

[18] Bell, V., Sigurdsson, S., Westenberg, J.J., et al. (2015) Relations between Aortic Stiffness and Left Ventricular Structure and Function in Older Participants in the Age, Gene/Environment Susceptibility-Reykjavik Study. Circulation: Cardiovascular Imaging, 8, e003039. https://doi.org/10.1161/CIRCIMAGING.114.003039

[19] Abhayaratna, W.P., Barnes, M.E., O’Rourke, M.F., et al. (2006) Relation of Arterial Stiffness to Left Ventricular Diastolic Function and Cardiovascular Risk Prediction in Patients $\geq 65$ Years of Age. American Journal of Cardiology, 98, 1387-1392. https://doi.org/10.1016/j.amjcard.2006.06.035

[20] Kaess, B.M., Rong, J., Larson, M.G., et al. (2016) Relations of Central Hemodynamics and Aortic Stiffness with Left Ventricular Structure and Function: The Framingham Heart Study. Journal of the American Heart Association, 5, e002693. https://doi.org/10.1161/JAHA.115.002693

[21] Bouthier, J.D., De Luca, N., Safar, M.E. and Simon, A.Ch. (1985) Cardiac Hypertrophy and Arterial Distensibility in Essential Hypertension. American Heart Journal, 109, 1345-1352. https://doi.org/10.1016/0002-8703(85)90364-3

[22] Eren, M., Gorgulu, S., Uslu, N., Celik, S., Dagdeviren, B. and Tezel, T. (2004) Relation between Aortic Stiffness and Left Ventricular Diastolic Function in Patients with Hypertension, Diabetes, or Both. Heart, 90, 37-43. https://doi.org/10.1136/heart.90.1.37

[23] Stratos, C., Stefanadis, C., Kallikazaros, I., Boudoulas, H. and Toutouzas, P. (1992) Ascending Aorta Distensibility Abnormalities in Hypertensive Patients and Response to Nifedipine Administration. The American Journal of Medicine, 93, 505-512. https://doi.org/10.1016/0002-9343(92)90577-X

[24] Malayeri, A.A., Natori, S., Bahrami, H., et al. (2008) Relation of Aortic Wall Thickness and Distensibility to Cardiovascular Risk Factors (from the Multi-Ethnic Study of Atherosclerosis [MESA]). American Journal of Cardiology, 102, 491-496. https://doi.org/10.1016/j.amjcard.2008.04.010 